Cornell Law Library

Scholarship@Cornell Law: A Digital Repository

Cornell Law Faculty Publications

Faculty Scholarship

$1-1-2006$

\title{
Assessing the SSRN-Based Law School Rankings
}

Theodore Eisenberg

Cornell Law School, ted-eisenberg@lawschool.cornell.edu

Follow this and additional works at: http://scholarship.law.cornell.edu/facpub

Part of the Applied Statistics Commons, Legal Education Commons, and the Legal Writing and $\underline{\text { Research Commons }}$

\section{Recommended Citation}

Eisenberg, Theodore, "Assessing the SSRN-Based Law School Rankings" (2006). Cornell Law Faculty Publications. Paper 423.

http://scholarship.law.cornell.edu/facpub/423

This Article is brought to you for free and open access by the Faculty Scholarship at Scholarship@Cornell Law: A Digital Repository. It has been accepted for inclusion in Cornell Law Faculty Publications by an authorized administrator of Scholarship@Cornell Law: A Digital Repository. For more information, please contact jmp8@cornell.edu. 


\title{
Commentary
}

\section{Assessing the SSRN-Based Law School Rankings}

\author{
THEODORE EISENBERG
}

One noteworthy feature of the SSRN-based rankings is the high correlation between them and other rankings. Black and Caron report correlation coefficients between their two Social Science Research Network (SSRN) school rankings (one based on downloads from SSRN and one based on the number of papers posted on SSRN) and six other published rankings. ' The correlations provide a useful and creative measure of consistency across studies. If ranking studies are highly correlated, then the least expensive and most efficient study to conduct can be used without incurring the expense and delay of the more labor-intensive ranking methods. SSRN has a substantial database and software that generates its rankings. SSRN-based rankings' correlations with other rankings raise the possibility that labor-intensive measures, such as those taken by U.S. News \& World Report ("U.S. News"), ${ }^{2}$ Eisenberg and Wells," and others, can be replaced by SSRN's more automated methodology.

This Commentary first suggests one way in which the SSRN correlations with other ranking studies are more limited than they first appear. SSRN correlations with other studies decrease in samples limited to schools that most directly compete-for example, in samples of schools ranked in the top 10 to 20 as measured by SSRN downloads. Under some reasonable approaches, no statistically significant correlations exist between SSRN downloads and other ranking systems. This is not to suggest that SSRN downloads provide little useful ranking information. That they provide some information about so many schools, without the need for labor-intensive methods, is important. They have the ability to identify schools that might otherwise appear in no ranking system. And, like any objective ranking system, they offer a method to rank all schools without depending on subjective opinions. But the use of SSRN downloads to distinguish among peer law schools - schools that in fact compete with one anothershould not be premised on their generally high correlations with other ranking studies across the full range of law schools.

Professors Black and Caron do not claim that SSRN rankings should replace the more labor-intenstive methods. My point is simply a caution for consumers of the rankings to use the rankings for purposes for which they are most appropriate. By adding a new set of objective metrics, SSRN should enable consumers to have more information than would otherwise be available. No one metric is so clearly the best such that ignoring others seems appropriate.

I then suggest one reason why SSRN-based rankings may be at a disadvantage compared to other objective ranking systems, particularly when one seeks to make fine

* Henry Allen Mark Professor of Law, Cornell Law School.

1. Bernard S. Black \& Paul L. Caron, Ranking Law Schools: Using SSRN to Measure Scholarly Performance, 81 IND. L.J. 83, 98-102 tbl.3 (2006).

2. USNEWS.COM, AMERICA'S BEST GRADUATE SCHOOLS 2006 (2005), http://www.usnews.com/usnews/edu/grad/rankings/rankindex_brief.php.

3. Theodore Eisenberg \& Martin T. Wells, Ranking and Explaining the Scholarly Impact of Law Schools, 27 J. LEGAL STUD. 373 (1998). 
distinctions among peer institutions. The SSRN database may provide less comprehensive coverage of downloads than competing systems, such as Westlaw and LexisNexis, provide about productivity and citations.

Finally, I suggest that SSRN's database offers the possibility to raise the standard of statistical analysis of ranking studies. It should take only limited additional programming to produce not just ordinal rankings but also other useful statistical outputs, such as meaningful clusters of schools.

\section{CORRElations AMONG RANKINGS OF PEer SCHOOLS}

The correlations based on ranks, reported in Black and Caron's table 5, are impressive, with coefficients ranging from .72 to .83 , and all correlations being statistically significant at or beyond the $1 \%$ level. ${ }^{4}$ If the research question is whether SSRN provides a ranking system that correlates with other systems throughout the full range of law schools, the answer is that it does. Further, SSRN supplies information that is clearly of some use.

But ranking the full range of schools often may not be the prime question of interest. Almost any ranking system can differentiate between the most elite and the least elite schools. One refinement of the full set of correlations is to examine how well the SSRN rankings correlate with others' rankings in subsets of the schools. Prospective students do not need a ranking system to know that the number one school is noticeably stronger than the number one hundred school or even the number twenty school. And schools do not regard themselves as competing with all other schools. Stanford and Harvard, for example, are more concerned with attracting students from one another than they are with attracting students from the schools ranked around number one hundred or number twenty. Students considering several law schools likely are considering choices among a fairly narrow range of rankings, not choices ranging from number one to number one hundred. Students have reasonable information about LSAT scores and GPAs, and sort themselves at the application stage.

One challenge for a ranking system is therefore the difficulty in differentiating among peer schools, however loosely defined "peers" might be. It is appropriate to ask not only whether rankings, including SSRN rankings, correlate with other rankings across a wide range of schools, but also whether rankings correlate with other rankings for relevant subsets of schools. For example, how well do the SSRN rankings correlate with other rankings in designating the top 10 law schools?

The following tables, based on Black and Caron's table 5, report the correlation coefficient and significance level for each of the studies Black and Caron assess. But panel A limits the sample to those schools that rank in the top 10 as measured by the number of SSRN downloads. Panel B limits the sample to those schools that rank in the top 15 as measured by SSRN downloads. Panel $\mathrm{C}$ limits the sample to those schools that rank in the top 20 as measured by SSRN downloads.

4. Black \& Caron, supra note 1 , at 107 tbl.5. 
Table 1. Correlations between different ranks

Panel A. Sample limited to top 10 law schools as ranked by SSRN downloads

\begin{tabular}{|c|c|c|c|c|c|c|c|}
\hline & \multicolumn{2}{|c|}{ SSRN } & \multicolumn{2}{|c|}{ Reputation } & \multicolumn{2}{|c|}{ Publications } & \multirow{2}{*}{$\begin{array}{c}\text { Citations } \\
\text { Eisenberg \& } \\
\text { Wells } \\
\end{array}$} \\
\hline & $\begin{array}{c}\text { Total } \\
\text { downloads }\end{array}$ & $\begin{array}{c}\text { Total } \\
\text { papers }\end{array}$ & $\begin{array}{c}\text { U.S. } \\
\text { News } \\
2006 \\
\end{array}$ & Leiter & $\begin{array}{c}\text { Lindgren \& } \\
\text { Seltzer }\end{array}$ & Leiter & \\
\hline SSRN total downloads & & & & & & & \\
\hline SSRN total papers & $.77^{*}$ & & & & & & \\
\hline U.S. News 2006 & .59 & $.68^{*}$ & & & & & \\
\hline Leiter reputation & $.68^{*}$ & .56 & $.86^{* \wedge}$ & & & & \\
\hline $\begin{array}{l}\text { Lindgren \& Seltzer } \\
\text { publications }\end{array}$ & .32 & .16 & .32 & .58 & & & \\
\hline Leiter publications & .55 & .36 & .32 & .52 & $.84^{*}$ & & \\
\hline $\begin{array}{l}\text { Eisenberg \& Wells } \\
\text { citations }\end{array}$ & $.70^{*}$ & $.64^{*}$ & $.87^{* 1}$ & $.81^{*}$ & .56 & .49 & \\
\hline Leiter citations & .59 & .59 & $.71 *$ & $.73^{*}$ & $.73^{*}$ & $.71^{*}$ & $.88^{* \wedge}$ \\
\hline
\end{tabular}

Panel B. Sample limited to top 15 law schools as ranked by SSRN downloads

\begin{tabular}{|c|c|c|c|c|c|c|c|}
\hline & \multicolumn{2}{|c|}{ SSRN } & \multicolumn{2}{|c|}{ Reputation } & \multicolumn{2}{|c|}{ Publications } & \multirow{2}{*}{$\begin{array}{c}\text { Citations } \\
\text { Eisenberg \& } \\
\text { Wells }\end{array}$} \\
\hline & $\begin{array}{c}\text { Total } \\
\text { downloads }\end{array}$ & $\begin{array}{c}\text { Total } \\
\text { papers }\end{array}$ & $\begin{array}{c}\text { U.S. } \\
\text { News } \\
2006\end{array}$ & Leiter & $\begin{array}{c}\text { Lindgren \& } \\
\text { Seltzer }\end{array}$ & Leiter & \\
\hline SSRN total downloads & & & & & & & \\
\hline SSRN total papers & $.72^{*}$ & & & & & & \\
\hline U.S. News 2006 & .46 & .45 & & & & & \\
\hline Leiter reputation & .44 & .34 & $.94^{* 1}$ & & & & \\
\hline $\begin{array}{l}\text { Lindgren \& Seltzer } \\
\text { publications }\end{array}$ & $.53^{*}$ & .38 & $.60^{*}$ & $.72 *$ & & & \\
\hline Leiter publications & .44 & .29 & $.69^{*}$ & $.76^{\star \wedge}$ & $.86^{* \wedge}$ & & \\
\hline $\begin{array}{l}\text { Eisenberg \& Wells } \\
\text { citations }\end{array}$ & .47 & .41 & $.93^{* 1}$ & $.93 * \wedge$ & $.71^{*}$ & $.75^{* \wedge}$ & \\
\hline Leiter citations & .43 & .41 & $.83^{* 1}$ & $.87^{* \wedge}$ & $.77 * \wedge$ & $.85^{* \wedge}$ & $.93^{* \wedge}$ \\
\hline
\end{tabular}

Panel C. Sample limited to top 20 law schools as ranked by SSRN downloads

\begin{tabular}{|c|c|c|c|c|c|c|c|}
\hline & \multicolumn{2}{|c|}{ SSRN } & \multicolumn{2}{|c|}{ Reputation } & \multicolumn{2}{|c|}{ Publications } & \multirow{2}{*}{$\begin{array}{c}\text { Citations } \\
\text { Eisenberg \& } \\
\text { Wells }\end{array}$} \\
\hline & $\begin{array}{c}\text { Total } \\
\text { downloads }\end{array}$ & $\begin{array}{l}\text { Total } \\
\text { papers }\end{array}$ & $\begin{array}{c}\text { U.S. } \\
\text { News } \\
2006\end{array}$ & Leiter & $\begin{array}{l}\text { Lindgren \& } \\
\text { Seltzer }\end{array}$ & Leiter & \\
\hline SSRN total downloads & & & & & & & \\
\hline SSRN total papers & $.75^{* 1}$ & & & & & & \\
\hline U.S. News 2006 & $.51^{*}$ & $.58^{*}$ & & & & & \\
\hline Leiter reputation & $.55^{*}$ & $.50^{*}$ & $.96^{* \wedge}$ & & & & \\
\hline $\begin{array}{l}\text { Lindgren \& Seltzer } \\
\text { publications }\end{array}$ & $.69^{* \wedge}$ & $.59^{*}$ & $.74^{* 1}$ & $.83^{* \wedge}$ & & & \\
\hline Leiter publications & $.45^{*}$ & .41 & $.76^{* 1}$ & $.78 * \wedge$ & $.82^{* \wedge}$ & & \\
\hline $\begin{array}{l}\text { Eisenberg \& Wells } \\
\text { citations }\end{array}$ & $.50 *$ & .44 & $.91^{* \wedge}$ & $.90^{* \wedge}$ & $.77^{* \wedge}$ & $.81^{* \wedge}$ & \\
\hline Leiter citations & $.61 *$ & $.53^{*}$ & $.84 * 1$ & $.88^{* \wedge}$ & $.85^{* \wedge}$ & $.82^{* \wedge}$ & $.93 * \wedge$ \\
\hline
\end{tabular}

* indicates significant at the $5 \%$ level

$\wedge$ indicates significant at $5 \%$ level after Sidak correction for multiple comparisons

NOTE: Spearman rank correlation coefficients for faculty quality measures determined using the indicated methodologies. Measures are defined in Black \& Caron, supra note 1. 
Panel A indicates that the SSRN-based rankings are significantly correlated $(p<.05)$ with the Leiter productivity ranking and the Eisenberg and Wells citationbased ranking. The superscript "^" symbols indicate those correlations that remain statistically significant after adjusting for multiple comparisons using the Sidak correction. ${ }^{5}$ After applying this admittedly conservative correction, the SSRN download rankings do not significantly correlate with any other studies. ${ }^{6}$ Only the Eisenberg and Wells and U.S. News rankings are significantly correlated with more than one other ranking system for the top 10 schools after the adjustment.

Figure 1 shows the relation among four ranking systems for schools ranked in the SSRN downloads top 10. The line represents the Eisenberg and Wells ranking as a reference point. One can see quite a tight fit between it and the Leiter 2003 citations ranking. Three of the schools in the SSRN top 10 download rankings are quite far from the citation-based measures. And three of the U.S. News rankings are far from the citation-based measures. The figure confirms what table 1, panel A suggests: a very high correlation between Eisenberg and Wells and Leiter 2003 citations, and between U.S. News and Leiter reputation rankings, while SSRN downloads have the lowest correlation with each of the three other ranking systems in the figure.

Of course, limiting the sample to ten observations reduces the likelihood of detecting statistically significant associations. Other factors being equal, larger samples provide greater statistical power than smaller samples. Panel B increases the sample to the top 15 schools, as measured by SSRN downloads. It indicates that the SSRN-based rankings are significantly correlated with the Lindgren-Seltzer ranking. The superscript " $\wedge$ " symbols again indicate those correlations that remain statistically significant after adjusting for multiple comparisons using the Sidak correction. After applying the correction, the SSRN download rankings do not significantly correlate with any other studies. The Eisenberg-Wells ranking and the Leiter reputation ranking are significantly correlated with four other ranking systems for the top 15 schools after the adjustment, and the Leiter citations ranking is significantly correlated with all five nonSSRN ranking methods.

Panel $\mathrm{C}$ increases the sample to the top 20 law schools, as measured by SSRN downloads. It indicates that the SSRN-based rankings are significantly correlated with all other ranking systems. But the superscript " $\wedge$ " symbols indicate that, after adjusting for multiple comparisons, SSRN downloads are significantly correlated only with the Lindgren and Seltzer ranking. All non-SSRN ranking systems remain significantly correlated with one another after adjusting for multiple comparisons.

5. Benjamin J. Winer, Donald R. Brown \& Kenneth M. Michels, Statistical PRINCIPLES IN EXPERIMENTAL DESIGN 165-66 (1991). Whether to adjust for multiple comparisons depends on the precise research question of interest. Sander Greenland \& Kenneth J. Rothman, Fundamentals of Epidemiologic Data Analysis, in MODERN EPIDEMIOLOGY 201, 227-29 (Kenneth J. Rothman \& Sander Greenland eds., 2d ed. 1998). Adjusting for all comparisons is appropriate if one is searching for pairwise correlations among any of the studied ranking methods. Other research hypotheses could be formulated about the relations among ranking methods, with a resulting different approach to multiple comparisons.

6. See WINER, ET AL., supra note S, at 166. 


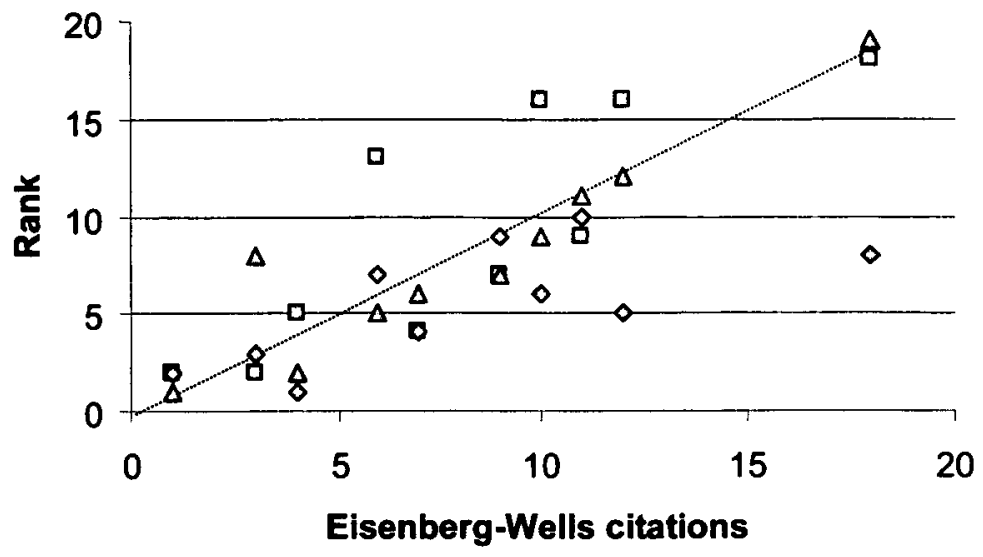

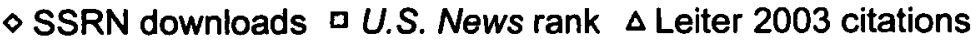

Figure 1. Scattterplot showing the relation between various ranking methodologies and Eisenberg and Wells citations. The sample consists of the top 10 ranked schools per SSRN downloads. A line representing Eisenberg and Wells citations has been added as a reference point.

That SSRN rankings are less often significantly associated with other rankings than the other ranking methods is only part of the story. An insignificant correlation and a significant correlation are not necessarily statistically significantly different. But it is not just the significance levels that differ. The size of the correlation coefficients also differs noticeably. For example, the median SSRN download correlation coefficient is significantly different from the median Eisenberg-Wells correlation coefficient $(p=.03)$ for the top 20 law schools. The combined evidence indicates that SSRN rankings are comparatively poorly correlated with other ranking systems in distinguishing among elite schools.

\section{THE COMPLETENESS OF THE SSRN DOWNLOAD DATABASE}

A ranking system depends on the database it uses to compute rankings. The ranking systems reported to date are based on large, reasonably comprehensive databases such as Westlaw and LexisNexis or on survey methodology such as that used by Leiter and U.S. News. A credible ranking system based on databases should be based on data that are reasonably comprehensive, or at least not biased across schools. My sense is that both Westlaw and LexisNexis are regarded as reasonably comprehensive in that a very substantial fraction of the citations to a work appear in those databases and in that a very substantial fraction of the works to be used in assessing productivity appear in those databases. SSRN is still developing and part of its rankings are based on downloads, not citations. Is it reasonable to assume that a very substantial fraction of download activity occurs through SSRN?

This question has not been seriously addressed and other download opportunities exist for users. Once published papers supersede working papers posted on SSRN, the published paper obviously becomes the preferred download document, and the published version may be available only from the publisher and not from SSRN. In addition, other download sites exist. What fraction of the downloads of a paper actually occur on SSRN? I offer some tentative numbers based on reasonably frequently 
downloaded papers by Professor Geoffrey Miller and me and by Professor Jonathan Macey and me. ${ }^{7}$

As of August 12, 2005, SSRN reports 655 downloads of Attorney Fees in Class Action Settlements: An Empirical Study (Cornell Legal Studies Research Paper No. 0401, 2004; NYU, Center for Law and Business Research Paper No. 03-23, 2004). The working paper is superseded by the published version, which appears in the Journal of Empirical Legal Studies (JELS). As of the end of 2004, the published paper had been downloaded from the official JELS website, maintained by Blackwell Publishing, 1089 times. ${ }^{8}$ The paper is also available from the New England Law Library Consortium (NELLCO). As of July 1, 2005, the attorney fees paper had been downloaded 241 times from that site. ${ }^{9}$ So SSRN accounts for 655 of about 1985 known downloads of the fees paper, or about $33 \%$ of known downloads. Similarly, SSRN lists, as of October 12, 2005, 534 downloads of the paper, Was Arthur Andersen Different? An Empirical Examination of Major Accounting Firms' Audits of Large Clients, by Jonathan Macey and me. NELLCO reports, as of July 1, 2005, 886 downloads of the same paper. ${ }^{10}$ And Blackwell reports, as of the end of 2004,187 downloads of the paper. ${ }^{11}$ So SSRN accounts for 534 of 1760 (about 30\%) of known downloads. One suspects that, for example, the Westlaw "tp-all" database accounts for a noticeably higher fraction of citations to a typical work of legal scholarship. Westlaw does not include many legal texts published by non-Thomson sources, so it is not complete. But, for the average law journal article, Westlaw likely contains substantially more than $33 \%$ or $30 \%$ of the sources that cite the article. One cannot know if the Eisenberg and Miller or Eisenberg and Macey articles are typical, but at least these articles' downloads are only modestly represented in SSRN. Moreover, the more successful a published article is, the smaller the fraction of its downloads that are likely to appear on SSRN. Users may go to the official publisher source or an official final version of an article rather than download a working paper. Until one has more confidence that SSRN more completely, or with little statistical bias, represents the universe of downloads, it is premature to regard SSRN download-based rankings as efficient, complete substitutes for more labor-intensive methods.

\section{METHODOLOgICAL OPPORTUNITIES REgUlaR SSRN RANKINGS PRESENT}

If SSRN decides to regularly rank law schools by its various measures, it would have the opportunity to improve the rigor of ranking studies. Ordinal rankings are

7. Theodore Eisenberg \& Geoffrey P. Miller, Attorney Fees in Class Action Settlements. An Empirical Study, 1 J. EMPIRICAL Legal STUD. 27 (2004); Theodore Eisenberg \& Jonathan R. Macey, Was Arthur Andersen Different? An Empirical Examination of Major Accounting Firm Audits of Large Clients, 1 J. EMPIRICAL LEGAL STUD. 263 (2004).

8. Blackwell Publishing, Publisher's Report: Confidential Report to Cornell Law School for the Publication Year 2004, Journal of Empirical Legal Studies 18 (2005) (unpublished report, on file with author).

9. E-mail from nellco.bepress.com to Theodore Eisenberg, Professor of Law, Comell Law School (Aug. 1, 2005) (on file with author).

10. E-mail from nellco.bepress.com to Theodore Eisenberg, Professor of Law, Cornell Law School (Oct. 3, 2005) (on file with author).

11. Blackwell Publishing, supra note 8. 
about all that most people take away from ranking studies. The ordinal rankings should be supplemented by reasonable statistical efforts to organize schools into statistically meaningful groups. Cluster analysis and related techniques, as applied to any of SSRN's metrics, should yield interesting groupings of law schools. So far as I know, only the Eisenberg and Wells rankings provided statistically supportable groupings of schools. Cluster analysis yielded previously unreported groupings of schools. ${ }^{12}$ And the statistical analysis of the groupings, using ANOVA and Kruskal and Wallis tests, also proved revealing. ${ }^{13}$ I believe SSRN would provide a substantial service to the law school and wider academic communities if it could help wean ranking systems off a singular focus on ordinal rankings. Meaningful groupings should be a part of any sophisticated academic ranking system.

Statistical progress is also possible on another front. Black and Caron report that strong correlations exist among their different measures and ranks. ${ }^{14}$ Factor analysis could quantitatively assess the degree to which the multiple measures are in fact measuring similar outputs. It may be that a single synthetic variable, constructed from the multiple measures, is a more satisfactory measure than is any individual measure. Other ranking systems based on multiple measures could be similarly scrutinized. For example, the many measures used by U.S. News may reduce to a handful of meaningfully different factors. Not all the information U.S. News gathers may be necessary to achieve essentially the same rigor in ranking.

Because SSRN's database is so automated, the benefits of cluster and factor analysis could be obtained through programming that simply took the current outputs that SSRN already has the ability to generate and passed them to a statistical program for further processing.

\section{CONCLUSION}

SSRN has potential advantages as a source of ranking. It includes a comprehensive list of schools and can automatically mine a large database. SSRN's automated data systems offer the opportunity to raise the standard of ranking methodology to wean consumers away from pure ordinal rankings and towards meaningful groupings. But this Commentary suggests two limitations of SSRN's current methodology. First, compared to other ranking systems, SSRN-based rankings fare poorly in discriminating among peer schools that may compete for students and faculty. Second, the SSRN database may contain a less complete collection of the items used for ranking than other databases. Specifically, SSRN may contain a lower percentage of downloads than Westlaw and LexisNexis contain of citations.

12. Eisenberg \& Wells, supra note 3, at 390-92.

13. Id.

14. Black \& Caron, supra note 1 , at 104-05. 